\title{
Maternal label and gesture use affects acquisition of specific object names
}

Article

Accepted Version

Online full text preprint

Zammit, M. and Schafer, G. (2011) Maternal label and gesture use affects acquisition of specific object names. Journal of Child Language, 38 (1). pp. 201-221. ISSN 0305-0009 doi: https://doi.org/10.1017/S0305000909990328 Available at https://centaur.reading.ac.uk/5735/

It is advisable to refer to the publisher's version if you intend to cite from the work. See Guidance on citing.

To link to this article DOI: http://dx.doi.org/10.1017/S0305000909990328

Publisher: Cambridge University Press

All outputs in CentAUR are protected by Intellectual Property Rights law, including copyright law. Copyright and IPR is retained by the creators or other copyright holders. Terms and conditions for use of this material are defined in the End User Agreement.

\section{www.reading.ac.uk/centaur}

\section{CentAUR}

Central Archive at the University of Reading

Reading's research outputs online 
7. Child Lang., Page I of 2 I. (C) Cambridge University Press 2010 doi:IO.IOI 7/So305000909990328

\title{
Maternal label and gesture use affects acquisition of specific object names*
}

\author{
MARIA ZAMMIT \\ Department of Psychology, University of Reading and Faculty of Health, \\ Leeds Metropolitan University
}

A N D

GRAHAM SCHAFER

Department of Psychology, University of Reading

(Received I May 2007 -Revised 29 Fanuary 2009-Accepted 7 October 2009)

\section{ABSTRACT}

Ten mothers were observed prospectively, interacting with their infants aged $\circ$; $\mathrm{o}$ in two contexts (picture description and noun description). Maternal communicative behaviours were coded for volubility, gestural production and labelling style. Verbal labelling events were categorized into three exclusive categories: label only; label plus deictic gesture; label plus iconic gesture. We evaluated the predictive relations between maternal communicative style and children's subsequent acquisition of ten target nouns. Strong relations were observed between maternal communicative style and children's acquisition of the target nouns. Further, even controlling for maternal volubility and maternal labelling, maternal use of iconic gestures predicted the timing of acquisition of nouns in comprehension. These results support the proposition that maternal gestural input facilitates linguistic development, and suggest that such facilitation may be a function of gesture type.

\section{INTRODUCTION}

There is considerable evidence linking the amount of speech mothers direct to their children, with the children's vocabulary growth (e.g. Furrow, Nelson \& Benedict, I979; Hoff-Ginsberg, I994; Hoff \& Naigles, 2002;

[*] The research described in this paper was supported by an ESRC doctoral studentship grant (No R42200I34423) to the first author. Address for correspondence: Maria Zammit, Faculty of Health, Leeds Metropolitan University, Civic Quarter, Calverley Street, Leeds, LS I 3HE. email:m.1.zammit@leedsmet.ac.uk 
Huttenlocher, Haight, Bryk, Seltzer \& Lyons, I 99ı; Rosenthal-Robbins, 2003). Huttenlocher et al. ( I 99 I) observed mothers during interaction with their children between $\mathrm{I} ; 5$ and 2 ; 0 , and reported that maternal volubility at I 4 predicted subsequent acceleration in children's vocabularies. TamisLeMonda, Bornstein \& Baumwell (200I) provide convincing evidence that in such relations the behaviour of mothers, rather than the children, is causal. Hoff-Ginsberg (1994) and Hoff \& Naigles (2002) also provide evidence that maternal volubility with children aged I;6 to 2 ; 0 is associated with child vocabulary growth. Hampson \& Nelson (r993) identified links between maternal speech to children aged I ; and children's productive vocabulary at $\mathrm{I} ; 7$, further suggesting a causal relation between maternal speech and vocabulary learning.

As pointed out by Goodman, Dale \& Li (2008), correlational studies provide only indirect evidence for the evaluation of the effect of frequency on word acquisition. Thus, despite numerous studies exploring the relation between general maternal volubility and child vocabulary development (e.g. Furrow et al., I979; Hoff-Ginsberg, I994; Hoff \& Naigles, 2002; Huttenlocher et al., I99I; Rosenthal-Robbins, 2003), few studies have explored the relation between maternal verbal production of SPECIFIC words and children's acquisition of those words. An exception is a training study reported by Schwartz \& Terrell (I983), in which children aged I; O to I ; 3 were exposed to novel words for objects and actions. Over ten training sessions, more frequently heard words were more likely to be acquired (i.e. used in later sessions) than were the less frequently heard ones. However, the referents used in this study were superordinate categories (e.g. 'objects at the end of a string'), while most early vocabulary is built at the basic level (e.g. Anglin, I977). Word category is an important consideration when investigating the relationship between frequency and acquisition. Goodman et al. (2008) compared age of acquisition data (from the MacArthur-Bates Communicative Development Inventories: Fenson, Marchman, Thal, Dale, Reznick \& Bates, 2007) for 562 words with estimates (from the CHILDES database: MacWhinney, 2000) of the frequency with which mothers produced those words in interaction with children aged $0 ; 7$ to $7 ; 6$. For the 562 words as a whole, parental frequency NEGATIVELY predicted age of acquisition, so that the more frequently a word was heard, the later it was learned! This counter-intuitive result arose because the more commonly encountered words are relatively hard to learn. In the corpus, closed-class categories were frequent but late-emerging; and even adjectives and verbs were more frequent than nouns, yet were learned later. Reassuringly, when the analysis was performed WITHIN categories, a more familiar pattern emerged, in which the more frequently a word was heard, the earlier it was learned. Furthermore, for comprehension data, parental frequency correlated only with the age of acquisition of nouns, and no other categories. 
The foregoing suggests that it is important to revisit training studies of the sort performed by Schwartz \& Terrell (1983), but to employ one lexical category at a time (most obviously, basic level nouns), and to study comprehension as well as production.

However, it is not just VERBAL input that is positively associated with vocabulary development. A growing body of work strongly suggests that Gestural input drives vocabulary (e.g. Bird, Gaskell, Babineau \& Macdonald, 2000; Goodwyn, Acredolo \& Brown, 2000; Namy, Acredolo \& Goodwyn, 2000; Rowe \& Goldin-Meadow, 2009). Given the findings of Goodman et al. that nouns are apparently the class most susceptible to the effects of parental input, and the need to develop the results of Schwartz \& Terrell (1983), the purpose of our study is to investigate prospectively the relation between maternal verbal and gestural labelling accompanying a set of common nouns, and the age at which children learn those nouns.

Brent \& Siskind (200I) report that the frequency with which children of I ; 2 heard words in isolation predicted the likelihood of these words being produced subsequently. We set out to explore the possibility that maternal verbal AND GESTURAL behaviour, prior to acquisition of a given word, predicts to some extent the timing of when the word will be learned. Because of the importance of word category to the role of frequency in vocabulary acquisition, we confine our investigation to one category: common nouns.

There is debate regarding the link between maternal gesture production and children's vocabulary. Although it has been suggested that frequent production of gesture by mothers impedes children's vocabulary growth (Rescorla \& Fechnay, I 996), others assert that maternal gestural production facilitates children's vocabulary growth (e.g. Bird et al., 2000; Goodwyn et al., 2000; Namy et al., 2000; Rowe \& Goldin-Meadow, 2009). Rescorla \& Fechney (1996) observed eighteen mothers during interaction with their sons aged I ; 6 to $2 ; 0$. Mothers of late talkers tended to produce rather more gesture than mothers of typically developing controls. However, the mothers of late talkers tended to produce more utterances that were unintelligible or unclear, suggesting that gesture production was not the only factor influencing late vocabulary growth. The findings of Rescorla and Fechney suggest that mothers gesture rather more with children when the child's vocabulary is limited, or gesture more alongside utterances that are difficult to understand without gestural support. The clarity of maternal speech may well influence children's vocabulary growth. Thus, a possible interpretation of Rescorla and Fechney's study is that mothers who do not speak clearly to children tend to compensate by producing more gestures to make themselves understood.

An association between maternal propensity to use gesture and children's vocabulary might be expected in the light of four sets of findings : ( I) children spontaneously learn gestures during interaction with their mothers 
(Acredolo \& Goodwyn, I 988); (2) children's gestural repertoire is positively associated with their concurrent verbal vocabulary (e.g. Iverson, Capirci, Longobardi \& Caselli, I999; Shatz, I982); (3) children can be taught both gestural and verbal symbols to refer to objects, requests and actions (e.g. Childers \& Tomasello, 2003); and (4) teaching children to produce symbolic gesture facilitates vocabulary growth (e.g. Goodwyn \& Acredolo, I 998; Namy et al., 2000).

In a series of studies Acredolo, Goodwyn, Namy and colleagues have demonstrated that teaching hearing children signs - in the form of symbolic gestures - facilitates vocabulary growth. Parents were trained to use symbolic gestures alongside verbal labels to refer to objects (e.g. flapping arms for 'bird', clawing motion for 'cat') during interactions with their children. Children were found to acquire the symbolic gestures, and to use them to refer to objects and to make requests. Two recent studies suggest that between o; I and I; 3 children interpret symbolic maternal gestures as object labels, demonstrating the capacity of typically developing children to attend to the gestural modality (Goodwyn et al., 2000; Namy et al., 2000). Goodwyn et al. (2000) followed up on a group of children who had participated in the gestural training study at o; I I. Children's language skill was assessed regularly from $\mathrm{I} ; 3$ to 3 ; o, revealing an advantage for the gesture-trained children in comparison with controls. Thus, actively instructing children in the use of symbolic gestures appears to accelerate vocabulary growth between $\mathrm{I} ; \mathrm{O}$ and $3 ; \circ$, thus demonstrating the multimodal nature of early symbolic reference. The pedagogical significance of gesture to word learning is further highlighted by Bird et al. (2000), who demonstrate that the use of signs alongside speech production can promote the acquisition of novel words in both typically developing children and those with Down Syndrome. Note, however, that the majority of studies reported above refer to the beneficial effects of iconic or symbolic gestures when produced ALONGSIDE verbal labels.

Inspection of the literature therefore suggests that three aspects of maternal communicative style may perhaps affect children's word learning: (I) overall volubility, in the form of the number of communicative acts directed towards children; (2) gestural production, in the form of the number of gestures directed towards children; and (3) maternal labelling style, in the form of the relative proportion of deictic and iconic gestures accompanying verbal labels.

To examine the potential causal relation between maternal communicative style and word learning, we explore links between maternal communicative behaviour when children have no knowledge of a specific set of target nouns, and the emergence of those target nouns in children's lexicon at two milestones in development: ( I) when the nouns were first reported as understood by children; and (2) when the nouns were reported to be produced. During the 
second year of life (the age of interest in the present study), parents often report a lag between children's first understanding a word, and their first saying it. This lag is considered by some to be as long as three to five months (e.g. Benedict, I 979; Fenson, Dale, Reznick, Bates, Thal \& Pethick, I 994), eventually reducing to zero at the age when a child can acquire and use a word on the same day (e.g. Carey \& Bartlett, i978). We therefore investigate links between comprehension and production milestones, and the various aspects of maternal communicative style discussed above.

In the context of research suggesting a strong link between maternal gestural production and children's vocabulary growth, it seems likely that mothers who direct higher NUMBERs of labels or gestures towards children will promote children's acquisition of target nouns. Labels may be produced either with or without accompanying gesture. We term verbal labels produced on their own, without gesture 'Labels Only' (LO), and in the light of the research reviewed above we predict that children of mothers who produce relatively high numbers of object labels will both understand and produce the target nouns earlier than average; while children of mothers who direct lower numbers of labels towards children will understand and produce target nouns later than average.

In addition to examining the relation between maternal production of labels unaccompanied by gesture, and word learning, we wish to examine the role of particular KINDS of gesture in promoting comprehension and production of object labels. Different information might in principle be of use at different times in development. For example, deictic (pointing) gestures, when produced alongside a verbal label, might facilitate vocabulary growth by highlighting the correspondence between noun and referent. Thus, given the early importance of pointing in communication even in the first year of life (e.g. Butterworth, 2003), maternal labelling acts accompanied by deictic gesture ('LD' acts) might be expected to correlate with acquisition of object labels in both comprehension and production. Given the early importance of pointing, we might expect this effect to be more strongly observed for comprehension than production. In distinction, maternal labelling accompanied by iconic gestures ('LI' acts) might be expected to act as a cue to word production, in a child who already knew a word. However, prediction is further complicated because, once word learning has started, some words are being learned in production, while others are still being learned in comprehension. For this reason, we seek in this initial study to establish whether gestural types are related to the timing of learning of sPECIFIC words in comprehension or production, or both, over a particular range of ages. We use a longitudinal design to examine the acquisition of a limited set of object names, in both comprehension and production, whilst prospectively examining maternal use of gesture IN THE CONTEXT OF THESE PARTICULAR OBJECT NAMEs. Acquisition of nouns was 
established using monthly parental report. A relationship between maternal communication at an early point in development, and the age at which target words emerge in children's lexicon would support the notion that maternal communicative style promotes lexical growth prospectively.

Different objects, and indeed different images of objects, afford differing gestural practices. Furthermore, different words tend be learned relatively early compared with other words (for group data in the USA, see Fenson et al., I994). We therefore designed a study in which individual mothers were compared in their use of gesture, and individual children for their lexical knowledge, regarding particular objects. For each object, we elicited maternal discussion with infants by using, on separate occasions, either an image of the object, or simply a verbal prompt (apple) to the mother. We intended this design to maximize differences between mothers while minimizing effects of items.

\section{METHOD}

\section{Participants}

The participants were ten British, white, middle-class mother-child dyads, recruited when the children were o; 9 . All ten mothers were educated to A-level standard (equivalent to the International Baccalaureate) or above, scoring at least 2 on the Educational status coding scheme in the Life Events and Difficulties schedule (Brown \& Harris, 1978). Each family scored 3.5 (middle-SES) or above on the Socio-Economic Status coding scheme, also in the Life Events and Difficulties schedule (Brown \& Harris, r978). All were married or living with partners, and were aged between twenty and forty years. Three mothers worked for ten hours or more per week outside the home, the remaining seven were full-time caregivers.

\section{Questionnaires}

A modified version of the MacArthur Communicative Development Inventory (CDI: (Fenson et al., I 994)) was administered to participants prior to each visit. No standardized parent reported measure of British children's gestural production existed before the start of the research. Therefore, we developed a parent-completed checklist of communicative development. The verbal section of the checklist was adapted from section A of the MacArthur CDI: Words and Sentences, and had previously been administered to British children (Tan \& Schafer, 2005), while the gestural section was adapted and extended from the MacArthur CDI: Words and Gestures (Fenson et al., I994). The verbal section of the instrument is notable because it combines aspects of both the CDIs described in Fenson et al. inasmuch as: (I) parents are asked to report on both comprehension and production; and (2) a large list of words is presented (663 in total). 
MATERNAL LABEL AND GESTURE USE

TABLE I. Object labels used in the study

\begin{tabular}{llcccl}
\hline Set & $\begin{array}{c}\text { Word } \\
\text { pair }\end{array}$ & $\begin{array}{c}\text { Age of } \\
\text { acquisition } \\
\text { (months) }\end{array}$ & Imageability $^{1}$ & Familiarity $^{1}$ & $\begin{array}{c}\text { Functional } \\
\text { category }\end{array}$ \\
\hline I & Apple & I $8 \cdot 4$ & $6 \cdot 5$ & $4 \cdot 48$ & Food \\
2 & Carrot & $22 \cdot 7$ & $6 \cdot 4$ & $4 \cdot 23$ & Food \\
I & Book & $22 \cdot$ I & $6 \cdot 05$ & $4 \cdot 68$ & Household item \\
2 & Pencil & I6.7 & $6 \cdot 35$ & $4 \cdot 0$ & Household item \\
I & Dog & $22 \cdot$ I & $6 \cdot 65$ & $4 \cdot 05$ & Animal \\
2 & Cat & $24 \cdot 4$ & $6 \cdot 4$ & $4 \cdot 0$ & Animal \\
I & Cup & $26 \cdot 2$ & $6 \cdot 5$ & $4 \cdot 59$ & Household item \\
2 & Bowl & I $7 \cdot 7$ & $5 \cdot 85$ & $4 \cdot 09$ & Household item \\
I & Boot & I5.2 & $6 \cdot 05$ & $4 \cdot 23$ & Clothing \\
2 & Shirt & $22 \cdot$ I & $6 \cdot 30$ & $4 \cdot 09$ & Clothing \\
\hline
\end{tabular}

${ }^{1}$ See Barry et al., I 997; Morrison et al., I 997.

\section{Procedure}

Mother-child dyads visited the laboratory monthly during the period the child was aged $0 ; 9$ to $2 ; 2$. During each visit, dyads were filmed in two experimental conditions (word and picture), as well as during an unstructured free interaction condition. In each of the two experimental conditions, a succession of words or pictures was projected onto the wall of the experimental room, in full view of both mother and child. Mothers were asked to talk to their child about each of them for $20 \mathrm{~s}$, until signalled to stop. So for instance, in the case of the word apple, mothers were presented with the word apple, or a picture of an apple, according to the condition. The purpose of using two conditions was to allow mothers two differing contexts for their potential use of gesture.

We identified ten nouns for mothers to talk to their children about during the recording sessions. These were apple, book, boot, bowl, carrot, cat, cup, $d o g$, pencil and shirt. Each month, five nouns were used, being presented to the dyad in both the word and picture format. Stimulus Set I contained the nouns: apple, boot, cat, cup and pencil, while Stimulus Set 2 contained the matched nouns book, bowl, carrot, dog and shirt. Sets were approximately matched for imageability, familiarity, functionality and age of acquisition in production, using norms published in Barry, Morrison \& Ellis (r997) and Morrison, Chappell \& Ellis ( r 997); see Table I. For example, 'apple' was matched to 'carrot' because both are food items, are acquired at approximately the same age (around $\mathrm{I} ; 6$ to $\mathrm{I} ; 8$ ), and score around 4.4 for imageability and around $6 \cdot 5$ for familiarity (Barry et al., I 997; Morrison et al., I 997). For a given child, then, sets were used bimonthly, to reduce overlearning of the particular stimuli. In any given month, half the children were presented with Set $\mathrm{I}$ in both picture and word conditions, while half 
were presented with Set 2 in picture and word conditions. Order of presentation was random within sets. Presentation order of the two verbal conditions (word or picture) was further counterbalanced across dyads.

The dyadic interactions took place in a comfortably furnished room, allowing for unobtrusive video recording of the sessions via a two-way mirror. The interactions were continuously filmed from the time the mother and child entered the room until they left it, including the informal break between verbal conditions, which lasted $2 \cdot 5$ minutes.

\section{Instructions to participants}

Mothers were informed: 'You will see five (words/pictures) presented one at a time on the wall in front of you. I would like you to talk to (child's name) about the things as you see them, (child's name) can join in as much as you both like. You will then have a short break, in which a blank slide will be seen. When it is time to begin the next part of the study some instructions will appear on the wall. During the second part of the study you will again see some more items on the wall. This time, they will be (pictures/words), again I would like you to talk to (child's name) about the things you see. Again (child's name) is free to join in.' Note that the instructions contain no reference to gesture.

\section{Coding and analysis}

The videotaped observations were coded with a scheme adapted from Iverson et al. ( I 999), previously used in this form by O'Neill, Bard, Linnell \& Fluck (2005). A single speech utterance was defined as any verbalisation followed by any of (a) a silence, (b) a change in conversational turns or (c) a change in intonation pattern, following criteria used by Iverson et al. ( I999). Each utterance was further classified in one of two exclusive categories: SPEECH ALONE, or SPEECH WITH GESTURE. (No examples of maternal gesture without speech were recorded in any of our sessions.) A gesture was defined as a hand, or arm, movement preceded and followed by a clear pause or relaxation of (e.g.) hand or arm position, following criteria used by Namy, Acredolo \& Goodwyn (2000). Speech with gesture was defined as any occasion in which a gesture was enacted in temporal overlap with an utterance.

\section{Types of maternal gestures}

Maternal gestures were coded as follows:

DEICTICGESTURES indicated the existence of an object, person or occurrence of an event (e.g. point to an object or event). 
ICONIC GESTURES referred in non-arbitrary fashion to objects, locations, individuals or events. Such gestures are often used to describe an attribute or action of an object, and differ from deictic gestures in that their meaning does not change across situations. Examples of such gestures might be: to mime the action of writing with a pencil, to mime drinking from a cup/eating from a bowl, or to use two hands to represent a book opening and closing.

EMPHATIC GESTURES serve to highlight aspects of discourse structure and/ or the content of accompanying speech. They are non-representational, have no specific semantic content or precise referent, and are not linked to a specific hand shape or facial expression. Nodding the head whilst stressing a particular noun or sentence would be an emphatic gesture, as would the making of circular motions with a flat hand during speech. These emphatic, or beat, gestures are typically executed in a rhythmic fashion during adult-adult speech (McNeill, I 998), but are rarely observed during adult-child speech (Iverson et al., I 999). These very rare gestures were noted but were too infrequent to be used in the analysis.

CONVENTIONAL GESTURES are those whose form and meaning are culturally defined and therefore consistent across time. Examples include shaking the head from side to side to indicate 'no', nodding the head up and down to indicate 'yes', and beckoning with either the whole hand or the index finger. These very rare gestures were noted but were too infrequent to be used separately in the analysis.

\section{Labelling targets with and without gesture}

The final subdivision of utterances was to identify all occurrences where mothers produced a label for the target nouns. Each of these utterances was placed into one of three exclusive categories. Occasions where the target word or picture was labelled without gestural support were recorded as LABEL WiTHOUT GESTURE (LO). Occasions where the target word or picture was labelled while pointing or otherwise motioning towards the target were recorded as LABEL PLUS DEICTIC GESTURE (LD). Occasions where the target word or picture was labelled with an accompanying iconic gesture were recorded as LABEL PLUS ICONIC GESTURE (LI).

\section{Reliability}

Inter-observer reliability measures were obtained on $10 \%$ of the videotaped observations. Inter-observer agreement for identifying maternal communicative acts was $94 \cdot 3 \%(N=323)$. Agreement for identifying gesture by type was $87 \cdot 7 \%(N=278)$. Agreement for identifying maternal labelling acts was $87 \cdot 5 \%(N=438)$. 
TABLE 2. Descriptive statistics for maternal measures, by task, taken on the first occasion the dyad encountered the word in the laboratory ${ }^{1}$

\begin{tabular}{|c|c|c|c|c|}
\hline & \multicolumn{2}{|c|}{ Word } & \multicolumn{2}{|c|}{ Picture } \\
\hline & Mean rate $(\mathrm{SD})$ & Range & Mean rate $(\mathrm{SD})$ & Range \\
\hline Total communicative acts & $33 \cdot 2(3 \cdot I)$ & $28 \cdot 0-37 \cdot 0$ & $3 I \cdot 6(5 \cdot 4)$ & I $7 \cdot 6-37 \cdot 5$ \\
\hline Speech without gesture ${ }^{\S}$ & $30 \cdot 2(3 \cdot 6)$ & $24 \cdot 3-36 \cdot 0$ & $27 \cdot 4(5 \cdot 4)$ & I $3.7-33.9$ \\
\hline Gestures* & $3 \cdot 0(I \cdot 2)$ & $I \cdot 0-4 \cdot 5$ & $4 \cdot 2(\mathrm{I} \cdot 5)$ & $2 \cdot 3-7 \cdot 2$ \\
\hline Labels without gesture** & $15 \cdot 2(4 \cdot 4)$ & $10 \cdot 3-26 \cdot 5$ & II $7(3 \cdot 0)$ & $7 \cdot 5-18 \cdot 5$ \\
\hline Labels with deictic gesture* & $2 \cdot 5(I \cdot I)$ & $0 \cdot 6-3 \cdot 9$ & $3.9(\mathrm{I} \cdot 5)$ & $I \cdot 3-6 \cdot 3$ \\
\hline Labels with iconic gesture & $0.3(0.4)$ & $0.0-0.9$ & $0.3(0.4)$ & $0 \cdot 0-1 \cdot 0$ \\
\hline
\end{tabular}

Difference between conditions: ${ }^{\S} p<0.10 ; * 0<0.05$; $* *$ * $p<0.0$ I (two-tailed).

${ }^{1}$ Rates per session of total maternal communicative acts (i.e. speech alone or speech with gesture), speech alone, maternal gestures and maternal labelling acts. See text.

\section{RESULTS}

We set out to investigate prospectively the relation between maternal labelling style many months prior to the emergence of target nouns in children's vocabulary and the age at which children learn those nouns. Although we are not primarily interested in task effects, it is prudent first to examine the effect of task (word versus picture description) upon maternal labelling style. We do this by reference to the first occasion the dyad encountered each target word in the laboratory. We then go on to examine the relationship between maternal labelling style and the emergence of the target words in children's vocabularies, at the level of individual words. Finally, we consider the relationship between maternal labelling style and the emergence of target words in children's comprehensive and productive vocabulary relative to the other children in the sample.

\section{Task and maternal labelling style}

We measured maternal communicative behaviour on the first occasion the dyad encountered the word in the laboratory task (and on which the average age of the child was $\circ ; 9^{\circ} 9$ : range $\left.0 ; 9^{\circ} \circ-\circ ; 10 \cdot 6\right)$ (see Table 2). Analysis of the types of communicative acts (i.e. speech alone or speech with gesture) aggregated across words for each task for each dyad, using the Wilcoxon signed ranks test, showed no effect of task $(Z(\mathrm{r} 0)=0.66, p=0.5 \mathrm{I})$. Marginally significant effects of task on speech acts without accompanying gesture $(Z(\mathrm{I} 0)=\mathrm{I} \cdot 95, p=0.05 \mathrm{I})$ and speech acts with accompanying gesture $(Z(\mathrm{I} 0)=2 \cdot 19, p=0.028)$ were observed. (All tests are two-tailed.) Significant effects of task were observed for maternal production of labelling acts without gesture $(Z(\mathrm{r} \circ)=2 \cdot 80, p=0.005)$ and labelling acts with deictic gesture $(Z(\mathrm{r} 0)=2.29, p=0.022)$, but not for labelling acts with iconic gesture 
$(Z(\mathrm{I} 0)=0.42, p=0.674)$. This pattern of results suggests that the extent to which mothers communicated using different communicative styles varied by task, and particularly so for communication involving gesture (because the rate of total communicative acts was unaffected by task). However, these are not particularly strong effects. Mothers tended to use verbal labels without accompanying gesture rather more frequently during the word than during the picture task. Conversely, and perhaps unsurprisingly, mothers used more speech with deictic gesture during the picture task than during the word task.

\section{Maternal labelling style and the emergence of individual words in children's vocabularies (item analysis)}

To establish the effect, if any, of maternal verbal and gestural communication on acquisition of nouns, we first conducted an analysis at the item level. Table 3 shows how mothers communicated the different nouns, at the first time they encountered them in the laboratory, in terms of the relative production rate per minute of each communicative act. These data are aggregated first across task, and then across dyad. Table 4 presents the age in months at which, according to mothers, each noun emerged in the children's lexicon of words comprehended (but not necessarily produced), and produced, averaged across children. It will be observed from Table 3 that the nouns attracted broadly similar levels of speech and gesture from mothers.

We conducted a series of Spearman's correlations to explore the relationship between the average age at which each target noun emerged in the children's (a) comprehension and (b) production lexicons and the aspects of maternal communicative style FOR THAT NOUN, as measured on the first occasion the dyad encountered the word in the laboratory: (I) overall volubility, as determined by the rate per minute of communicative acts directed towards children; (2) gestural production, as determined by the rate per minute of gestures directed towards children; and (3) maternal labelling style, as determined by the rate per minute of labelling acts within each category (i.e. label only; label plus deictic gesture; label plus iconic gesture). In this analysis, we found very little evidence of consistent relations between maternal communicative behaviour at the level of individual words, and the emergence of individual items in children's comprehension or production lexicons. This lack of an effect at the item level may be a function of the relatively even distribution of the amount of communication across the nouns, as seen in Table 3 .

\section{Overall relationship between maternal labelling style and the emergence of target words}

In the foregoing item analysis, we considered the relationship between maternal gestures when talking about particular nouns, and the age of 
TABLE 3. Communicative acts, by noun: rate per minute to two significant figures or one decimal place

\begin{tabular}{|c|c|c|c|c|}
\hline Noun & & Mean & Minimum & Maximum \\
\hline \multirow[t]{5}{*}{ Apple } & Total communicative acts & $3 I \cdot 7$ & $23 \cdot 4$ & $42 \cdot 4$ \\
\hline & Speech without gesture & $29 \cdot 4$ & $2 I \cdot 0$ & $40 \cdot 9$ \\
\hline & Gestures & $2 \cdot 3$ & $\circ$ & $4 \cdot 5$ \\
\hline & Labels without gesture & I $7 \cdot 4$ & $7 \cdot 5$ & $27 \cdot 0$ \\
\hline & Labels with deictic gesture & $2 \cdot 9$ & $\circ$ & $4 \cdot 5$ \\
\hline \multirow[t]{5}{*}{ Book } & Total communicative acts & $34 \cdot 3$ & $2 \mathrm{I} \cdot 3$ & $46 \cdot 5$ \\
\hline & Speech without gesture & $3 I \cdot 3$ & $19 \cdot 8$ & $37 \cdot 5$ \\
\hline & Gestures & $3 \cdot 0$ & $\circ$ & $9 \cdot 0$ \\
\hline & Labels without gesture & I $5 \cdot 0$ & $9 \cdot 0$ & 19.5 \\
\hline & Labels with deictic gesture & $2 \cdot 25$ & $\circ$ & $6 \cdot 0$ \\
\hline \multirow[t]{5}{*}{ Boot } & Total communicative acts & $33 \cdot I$ & $2 I \cdot 0$ & $40 \cdot 9$ \\
\hline & Speech without gesture & $29 \cdot 3$ & I $6 \cdot 5$ & $40 \cdot 9$ \\
\hline & Gestures & $3 \cdot 9$ & $\circ$ & $4 \cdot 5$ \\
\hline & Labels without gesture & $12 \cdot 6$ & $6 \cdot 0$ & $25 \cdot 5$ \\
\hline & Labels with deictic gesture & $3 \cdot 5$ & $\circ$ & $4 \cdot 5$ \\
\hline \multirow[t]{5}{*}{ Bowl } & Total communicative acts & $33 \cdot 2$ & $21 \cdot 3$ & $4 \mathrm{I} \cdot \mathrm{I}$ \\
\hline & Speech without gesture & $29 \cdot 5$ & I9.8 & $37 \cdot 5$ \\
\hline & Gestures & $3 \cdot 8$ & $\mathrm{I} \cdot 5$ & $7 \cdot 5$ \\
\hline & Labels without gesture & I 4.4 & $9 \cdot 0$ & $25 \cdot 5$ \\
\hline & Labels with deictic gesture & $3 \cdot 2$ & $\mathrm{I} \cdot 5$ & $7 \cdot 5$ \\
\hline \multirow[t]{5}{*}{ Carrot } & Total communicative acts & $33 \cdot 2$ & $2 \mathrm{I} \cdot 3$ & $42 \cdot 0$ \\
\hline & Speech without gesture & $30 \cdot 7$ & $19 \cdot 8$ & $39 \cdot 0$ \\
\hline & Gestures & $2 \cdot 6$ & $\circ$ & $6 \cdot 0$ \\
\hline & Labels without gesture & $\mathrm{I} 2 \cdot 2$ & $7 \cdot 5$ & $2 I \cdot 0$ \\
\hline & Labels with deictic gesture & $2 \cdot 3$ & $\circ$ & $4 \cdot 5$ \\
\hline \multirow[t]{5}{*}{ Cat } & Total communicative acts & $33 \cdot 5$ & $24 \cdot 9$ & $48 \cdot 9$ \\
\hline & Speech without gesture & $29 \cdot 4$ & $21 \cdot 0$ & $40 \cdot 9$ \\
\hline & Gestures & $4 \cdot I$ & $\mathrm{I} \cdot 5$ & $9 \cdot 0$ \\
\hline & Labels without gesture & I 3.9 & $9 \cdot 0$ & $24 \cdot 0$ \\
\hline & Labels with deictic gesture & $3 \cdot 2$ & $\mathrm{I} \cdot 5$ & $6 \cdot 0$ \\
\hline \multirow[t]{5}{*}{ Cup } & Total communicative acts & $34 \cdot 4$ & $27 \cdot 9$ & $42 \cdot 4$ \\
\hline & Speech without gesture & $30 \cdot 3$ & $23 \cdot 4$ & $40 \cdot 9$ \\
\hline & Gestures & $4 \cdot \mathrm{I}$ & $\circ$ & $7 \cdot 5$ \\
\hline & Labels without gesture & I 3.9 & $7 \cdot 5$ & I $6 \cdot 5$ \\
\hline & Labels with deictic gesture & $3 \cdot 9$ & $\circ$ & $7 \cdot 5$ \\
\hline \multirow[t]{5}{*}{ Dog } & Total communicative acts & $35 \cdot \circ$ & $24 \cdot 3$ & $42 \cdot 0$ \\
\hline & Speech without gesture & $30 \cdot 5$ & I9.8 & $37 \cdot 5$ \\
\hline & Gestures & $4 \cdot 5$ & $3 \cdot 0$ & $6 \cdot 0$ \\
\hline & Labels without gesture & I $3 \cdot I$ & $4 \cdot 5$ & $25 \cdot 5$ \\
\hline & Labels with deictic gesture & $4 \cdot \mathrm{I}$ & $\mathrm{I} \cdot 5$ & $6 \cdot 0$ \\
\hline \multirow[t]{5}{*}{ Pencil } & Total communicative acts & $32 \cdot 7$ & $27 \cdot 0$ & $40 \cdot 9$ \\
\hline & Speech without gesture & $28 \cdot 2$ & I 5.0 & $40 \cdot 9$ \\
\hline & Gestures & $4 \cdot 5$ & $\circ$ & I $2 \cdot 0$ \\
\hline & Labels without gesture & I I $\cdot$ I & $6 \cdot 0$ & I $6 \cdot 5$ \\
\hline & Labels with deictic gesture & $2 \cdot 7$ & $\circ$ & $6 \cdot 0$ \\
\hline \multirow[t]{5}{*}{ Shirt } & Total communicative acts & $33 \cdot 7$ & $2 \mathrm{I} \cdot 3$ & $42 \cdot 0$ \\
\hline & Speech without gesture & $29 \cdot 0$ & I9.8 & $37 \cdot 5$ \\
\hline & Gestures & $4 \cdot 65$ & $\mathrm{I} \cdot 5$ & $7 \cdot 5$ \\
\hline & Labels without gesture & $12 \cdot 9$ & $9 \cdot 0$ & $22 \cdot 5$ \\
\hline & Labels with deictic gesture & $4 \cdot 7$ & $\mathrm{I} \cdot 5$ & $7 \cdot 5$ \\
\hline
\end{tabular}


TAB LE 4. Children's ages at comprehension and production of each target noun, according to parental report

\begin{tabular}{|c|c|c|c|c|}
\hline \multirow[b]{2}{*}{ Item } & \multicolumn{2}{|c|}{ Age at comprehension (months) } & \multicolumn{2}{|c|}{ Age at production (months) } \\
\hline & Mean (SD) & Range & Mean (SD) & Range \\
\hline Apple & I $3.9(4.5)$ & $9 \cdot 0-19 \cdot I$ & I $7 \cdot 8(2 \cdot 6)$ & $14 \cdot 0-20 \cdot 9$ \\
\hline Book & II $\cdot 7(2 \cdot 5)$ & $9 \cdot 0-14 \cdot 9$ & I $7 \cdot I(2 \cdot 4)$ & $\mathrm{I} 4 \cdot 0-20 \cdot \mathrm{I}$ \\
\hline Boot & $\mathrm{I} 4 \cdot 3(4 \cdot 3)$ & $9 \cdot 0-19 \cdot 9$ & $20 \cdot 1(2 \cdot 6)$ & I $5.0-23.5$ \\
\hline Bowl & I $4 \cdot 5(4 \cdot 3)$ & $9 \cdot 0-I 9 \cdot I$ & $2 \mathrm{I} \cdot 0(2 \cdot 9)$ & I $6 \cdot 0-26 \cdot I$ \\
\hline Carrot & I6.9 $(3.5)$ & $9 \cdot 0-2 I \cdot 2$ & $2 \mathrm{I} \cdot 2(2 \cdot 9)$ & I $6 \cdot 0-26 \cdot I$ \\
\hline Cat & I $3 \cdot 3(2 \cdot 9)$ & $9 \cdot 0-17 \cdot 3$ & $17 \cdot 0(2 \cdot 3)$ & $13 \cdot 0-19 \cdot 8$ \\
\hline Cup & I $3.9(3.6)$ & $9 \cdot 0-18 \cdot 4$ & $20 \cdot 6(3 \cdot 0)$ & I $5 \cdot 0-26 \cdot I$ \\
\hline Dog & $\mathrm{II} \cdot 4(2 \cdot 5)$ & $8 \cdot 8-\mathrm{I} 6 \cdot 0$ & I $5.9(\mathrm{I} \cdot 9)$ & I $3 \cdot \mathrm{I}-\mathrm{I} 8 \cdot 4$ \\
\hline Pencil & I $3.8(4.6)$ & $9 \cdot 0-20 \cdot 9$ & $2 \mathrm{I} \cdot \mathrm{I}(3 \cdot 4)$ & I $5 \cdot 0-26 \cdot \mathrm{I}$ \\
\hline Shirt & I $3.6(4 \cdot 5)$ & $9 \cdot 0-\mathrm{I} 9 \cdot \mathrm{I}$ & $21 \cdot 6(2 \cdot 7)$ & I $6 \cdot 0-26 \cdot I$ \\
\hline
\end{tabular}

acquisition of those nouns. Our analysis so far suggests that there may be at best a weak relation between maternal production of communicative acts and children's acquisition of target nouns, at the word level - at least as observed in the current study. It is, however, possible that relations exist between communicative style and learning of words, but these are masked by the small size of the sample $(N=\mathrm{ro})$, and the relatively large variation in individuals' vocabulary growth. That is, differences may well be easier to observe between children than between items. For this reason, we present a final analysis in which we examine the relationship between maternal labelling style and the emergence of targets in each child's comprehensive and productive vocabulary, MEASURED RELATIVE TO OTHER CHILDREN IN THE SAMPLE. This analysis averages across words, within children. Compared with the item analysis, it is a more direct test of whether differences in acquisition are governed by differences between dyads.

Data for the acquisition of individual words by children in the study, as reported by mothers, is given in Table 4 . For the group as a whole, averaged across children, target labels were reported as comprehended at $1 ; 3.3$ and produced at $\mathrm{I} ; 6 \cdot 7$. To establish the effect, if any, of maternal verbal and gestural communication on acquisition of the nouns in the study, it is necessary to establish if particular children learn to comprehend or produce labels relatively early, or relatively late, in comparison with their peers, across all the nouns used in the study. Table 5 gives the difference in months between the age at which each child was reported to acquire target words in comprehension and production, and the group age of acquisition of these nouns. This measure, calculated for each child across the ten target nouns, we term the RELATIVE ADVANCEMENT of the acquisition of the nouns. Positive values indicate that the child learned the words, as a whole, later 
TABLE 5. Relative advancement, in months, in individual ages of acquisition of object labels, by dyad, in comparison with group mean

\begin{tabular}{|c|c|c|c|c|c|c|c|c|c|c|}
\hline \multirow{2}{*}{$\begin{array}{l}\text { Mean relative } \\
\text { advancement, } \\
\text { compared with } \\
\text { group (across } \\
\text { ten nouns) }\end{array}$} & \multicolumn{10}{|c|}{ Dyad } \\
\hline & A & B & $\mathrm{C}$ & $\mathrm{D}$ & $\mathrm{E}$ & $\mathrm{F}$ & $\mathrm{G}$ & $\mathrm{H}$ & I & $\mathrm{J}$ \\
\hline Comprehension & 0.9 & $2 \cdot I$ & $-I \cdot O$ & $2 \cdot 3$ & $-3 \cdot 2$ & -0.9 & $2 \cdot 0$ & $-\mathrm{I} \cdot 4$ & $0 \cdot I$ & -0.2 \\
\hline Production & 0.4 & $\mathrm{I} \cdot 8$ & $3 \cdot 0$ & $\mathrm{I} \cdot 6$ & -0.9 & -0.5 & $\mathrm{I} \cdot 7$ & $-4 \cdot 4$ & -0.4 & $-I \cdot 4$ \\
\hline
\end{tabular}

NOTE: Negative numbers: acquisition earlier than the group as a whole.

than the group. (Note that the measure is conservative, because individual children contribute to the group mean from which their relative advancement is calculated.)

To explore the relationship between the relative advancement of the emergence of the ten nouns in the children's lexicons, and measures of maternal communicative style, we aggregated noun data (for relative advancement of comprehension/production data and for maternal communicative behaviour) across words within dyad, and then conducted Spearman correlations between the relative advancement measures and maternal communication measures, across the ten dyads. Maternal communication measures were those taken on the first occasion the dyad encountered the word in the laboratory (and on which the average age of the child was $0 ; 9 \cdot 9$, range $0 ; 9.0-0 ; 10.6)$, and are: (I) the rate per minute of communicative acts directed towards the child; (2) the rate per minute of gestures directed towards the child; and (3) maternal labelling style, as determined by the rate per minute of labelling acts within each category (label only: 'LO'; label plus deictic gesture: 'LD'; and label plus iconic gesture: 'LI'). The correlations are presented in Table 6. All correlations were predicted to be positive and so all tests of significance are one-tailed.

As might be expected, relative advancement measures were intercorrelated. Maternal communicative acts correlated with our measure of the relative age of acquisition in understanding, but not with its equivalent for productive learning. The number of gestures did not correlate with either of the child measures. However, there was a reliable relationship between all of the measures of maternal labelling and when words were first comprehended. From these data, it is clear that the frequency with which mothers verbally labelled the objects to their children before the end of the first year predicted the timing of the subsequent appearance of those items in the child's vocabulary, for both comprehension and production, according to parental report: the more frequently mothers had been observed to label or gesture to their children at age o; $о$, the earlier their 
TABLE 6. Correlations between the relative advancement of acquisition of target words and maternal measures taken on the first occasion the dyad encountered the word in the laboratory

\begin{tabular}{lccccc}
\hline & \multicolumn{5}{c}{ Mother measures } \\
\cline { 2 - 6 } & $\begin{array}{c}\text { Total } \\
\text { communicative } \\
\text { acts }\end{array}$ & Gestures & LO & LD & LI \\
\cline { 3 - 6 } $\begin{array}{c}\text { Relative advancement } \\
\text { in comprehension }\end{array}$ & $0.55^{*}$ & 0.26 & $0.59^{*}$ & $0.55^{*}$ & $0.66^{*}$ \\
$\begin{array}{l}\text { Relative advancement } \\
\text { in production }\end{array}$ & 0.33 & 0.27 & $0.74^{* *}$ & $0.69^{*}$ & $0.55^{*}$ \\
\hline
\end{tabular}

$* p<0.05 ; * * 0<0.0 \mathrm{I}$ (one-tailed).

LO : label only; LD: label plus deictic gesture; LI : label plus iconic gesture.

child was reported to know the words in the study, for both comprehension and production. This is a clear linguistic finding at the level of individualwords-within-dyad, and not unexpected given previous studies outlined in the introduction.

Furthermore, it appears from the data in Table 5 that maternal labelling practices, as they relate to gesture, are associated with the relative age of acquisition of the target nouns: there are reliable correlations between label use with gesture (either deictic or iconic) and our measures of relative advancement in both comprehension and production. However, such a conclusion must be tentative, because there is at least as good a correlation between labelling on its own (LO) and the child measures. Hence, a parsimonious conclusion of our data might be that labelling on its own is the key variable, and that any gestures accompanying labels are irrelevant, merely serving not to disrupt a positive relation between age of acquisition of object labels and maternal labelling frequency.

To explore further the role of gestures in the differential age of acquisition data, we divided each mother's rate of labelling with gesture (LD, LI in Table 6) by her rate of labelling without gesture (LO), and re-performed the Spearman correlations. In this analysis, the LI (verbal labelling accompanied by iconic gesture) measure remained reliably correlated with relative advancement in comprehension $(\rho=0.70, p=0.012)$. Other correlations were non-significant. As a check on the generality of this finding, we performed partial correlations of each of the three labelling types, with our relative advancement measures, controlling for total communicative acts. Reliable relationships were observed between labelling with iconic gestures (LI) and relative advancement in comprehension $(r=0.69, p=0.0 \mathrm{I} 2)$ and between labelling without gesture (LO) and relative advancement in 
production $(r=0.86, p=0.002)$. Because $N$ is so low $(N=\mathrm{I} 0)$, not too much store should be set by this analysis, but we believe it does serve to support the conclusion that there is a positive relationship between maternal use of iconic gesture and acquisition of object labels in comprehension, independent of volume of maternal use of verbal labels.

\section{DISCUSSION}

We set out to explore the relation between maternal communicative behaviour and the emergence of the ten target nouns in the child's lexicon. We operationalized communication in terms of the rate per minute of communicative acts, use of gesture, use of verbal labels and the way in which verbal nouns and gestures were combined, at the level of individual words. We found strong links, at the child level, between most of these measures and the speed of entry of words into the lexicon.

In the two tasks we used to elicit gesture, mothers tended to use verbal labels without accompanying gesture more frequently during the word than during the picture task; they used more speech with deictic gesture more during the picture task than during the word task. Neither of these results is particularly surprising.

\section{The effects of overall maternal volubilityand overall gestural production}

We observed a significant association between maternal volubility (in this case total maternal communicative acts) and the emergence of target nouns in children's comprehension vocabulary, i.e. for the point at which words are understood but not yet said; however, we did not observe a significant association between maternal volubility and the emergence of target nouns in children's productive vocabulary. Our data suggest that children of mothers who produced large numbers of communicative acts learn words earlier than children of mothers who produced fewer communicative acts. This result is in line with literature suggesting that maternal volubility predicts children's vocabulary (cf. Furrow et al., I979; Hoff-Ginsberg, I 994; Hoff \& Naigles, 2002; Huttenlocher et al., I 99 I ; Rosenthal-Robbins, 2003). The less reliable relationship between maternal volubility and PRODUCTION may be explained in the report of Barrett, Harris \& Chasin (I99I), who suggest that maternal ostensive labelling is particularly important for the acquisition of EARLY emerging words. Barrett et al. demonstrated a link between maternal speech and the emergence of children's first ten words only, suggesting that links between linguistic input and lexical development decline after children have started to learn words. This would suggest that, as we have recorded, maternal volubility 
would be better related to comprehension than production, because the former occurs earlier.

\section{The effects of maternal labelling style}

We observed some interesting relations between maternal production of each type of labelling act and the emergence of targets both as words understood but not said, and as words produced. The emergence of target words as items in comprehension vocabulary was correlated with mother's production of labels on their own and labels accompanied by gestures; so was the emergence of target words as items in production vocabulary. However, once maternal propensity to produce labels was controlled for, the only statistical relationship which was preserved for gesture was that between the emergence of target words as items in COMPREHENSION vocabulary, and maternal use of labels with ICONIC gestures. We take this as reasonable evidence that iconic gestures can boost children's early learning of labels for objects in comprehension, over and above any effects of maternal speech. This result came as something of a surprise, given our initial analysis, presented in the introduction, that iconic gesture might be expected to support emergence of productive use of a word which had already been learned.

One of the aims of this study was to investigate the extent to which maternal verbal volubility facilitates children's acquisition of targets. We were unable to detect such an effect at the level of individual items. That is, we failed to show convincingly that variation in mothers' use of communicative acts (whether with or without gesture), in the case of particular words, was linked to the timing of acquisition of those words. This is perhaps not surprising, given our small sample $(N=\mathrm{r} 0)$ and the wide differences between dyads, which is both a commonplace in the literature (e.g. Huttenlocher et al., I99I) and observed in our study. However, once we analyzed the data at the level of the dyad, strong patterns emerged. We observed a significant association between overall communicative volubility and the emergence of targets as items understood but not said. We further observed significant relationships between the number of labels mothers provided both with and without accompanying gesture, and the emergence of target words in both comprehension and production vocabularies. It does appear that mothers who labelled items frequently for children promoted the rapid learning of specific target words; this relation was strongest for the emergence of items in productive vocabulary.

From the foregoing, we conclude, perhaps not surprisingly, that the children who hear the labels of targets most often tend to learn these targets more quickly than their peers. Although the relation between maternal volubility and children's concurrent and predicted vocabulary size has been 
widely explored, it can be difficult to disentangle the effects of children's responsiveness from the causal effects of maternal behaviour (for a discussion, see Tamis-LeMonda et al., 200I). The strength of this study is that we explored the relation between maternal labelling AS DIRECTED TOWARDS PARTICULAR NOUN LABELS, many months before children knew the target nouns, and established a link between this behaviour and the emergence of targets.

Recent research has revealed a correlation between maternal production of iconic gestures and the concurrent number of words in children's productive vocabulary: mothers tend to use iconic gestures with children who tend to produce a lot of words (Zammit \& Schafer, in preparation). In the present study, maternal use of iconic gestures alongside labelling during interaction when the child had no reported vocabulary knowledge of the label (and was only o; 9 or o; 10 ) was positively associated with subsequent rapidity of acquisition of those target nouns in comprehension. Goodwyn et al. (2000) showed that training mothers in greater use of iconic gesture during interaction with children aged o; I I facilitated subsequent vocabulary growth. Our findings suggest that some mothers do not require training because they already 'know' about the facilitative function of iconic gesture when 'teaching' words to children. Note that we are not suggesting that these mothers are NECESSARILY explicitly aware of the benefits of gesturing to children, but simply that some mothers naturally use gesture to facilitate children's learning about words.

There is a growing body of work demonstrating that symbolic gesture emerges earlier than symbolic speech (Bonvillian, Orlansky \& Folven, I 990; Goodwyn \& Acredolo, I 993; I 998 ; Zammit \& Schafer, in preparation). Such research has tended to focus on the modality advantage for sign language over spoken language, although Iverson, Capirci \& Casselli ( I 994), studying the development of gesture and speech in six hearing Italian infants aged I;O-I;6, found evidence of an early modality advantage for GESTURE over speech. The research of Namy et al. (2000) takes this a step further, identifying an advantage for the gestural modality in comprehension. It is possible that iconic gestures are important to comprehension because they assist the child's recall of object labels. There are at least two ways in which this might occur: (I) the iconic gesture captures and retains the child's attention to the mother's speech, thereby making the event more memorable; or (2) the iconic gesture adds information, in an orthogonal modality to that of speech, which helps the child retain and recall the association between word and object. (This latter notion is perhaps supported by research demonstrating that memories are more accurately recalled when body positions during retrieval of autobiographical events are similar to the body positions in the original events than when body position was incongruent; Dijkstra, Kaschak \& Zwaan, 2007). Thus, the facilitative link between 
maternal production of iconic gesture and vocabulary growth may be a function of the simplicity, or salience, of the gestural modality, relative to the verbal modality. Given this, it is perhaps not surprising that maternal production of iconic gesture correlates with children's acquisition of the understanding of particular words.

Our findings suggest that mothers who frequently LABEL items while describing them facilitate children's rapid comprehension, and production, of object labels. Such facilitation is more than a mere effect of volubility: our 'label' measures were more strongly associated with advancement in the age of acquisition of items than was the 'speech' measure. Several researchers have highlighted a link between maternal production of nouns and the number of nouns in children's productive vocabulary (e.g. D’Odorico, Carubbi, Salerni \& Calvo, 200 ; Nelson, r 973). Nelson ( 1973 ) first identified the referential-expressive distinction in children's productive vocabulary: children classified as having a 'referential' speech style had vocabularies biased towards nouns, while children classified with an 'expressive' speech style had vocabularies biased towards social routine words. The referential-expressive distinction has been associated with maternal speech style. Maternal production of directive speech has been associated with children's preference for expressive language (Della Corte, Benedict \& Klein, I983), while referential maternal speech is associated with children's preference for referential speech. Such relations are present from the end of the first year: one-year-olds exposed to referential speech (naming and object description) have more nouns in their vocabularies than children exposed to directive speech (Reznick \& Goldfield, I994). More recently, Tan \& Schafer's (2005) investigation into children's acquisition of novel words in a laboratory-based preferential-looking test suggested positive associations between maternal self-reports of frequency of referential acts ('pointing out') and children's rapid word learning. It is easy to see how frequent exposure to referential communication promotes the acquisition of nouns over, for example, social terms; while exposure to directive communication promotes the acquisition of social words.

The present research has exposed relations between maternal labelling style and children's acquisition of object names. In terms of gesture in particular, maternal production of labels accompanied by iconic gestures tended to promote more rapid comprehension of targets, but not rapid production of targets. We (Zammit \& Schafer, in preparation) have also demonstrated that children's CURRENT PRODUCTIVE vocabulary can also in certain circumstances be associated with maternal production of iconic gesture. Mothers tended to use fewer iconic gestures with children who had a relatively small vocabulary. Thus, it seems that although iconic gestures are produced infrequently they are important for vocabulary growth. As noted by Namy et al. (2000), iconic gestures offer children an accessible 
entry to the communicative world, in terms of both comprehension and production. Similarly, our findings have revealed strong links between the maternal tendency to name objects with and without gesture and the emergence of items in children's vocabulary. Once more we see the importance of caregiver behaviour in the facilitation of language growth in children.

\section{REFERENCES}

Acredolo, L. \& Goodwyn, S. (1988). Symbolic gesturing in language development. Child Development 59, 450-66.

Anglin, J. A. (1977). Word, object, and conceptual development. New York: W. W. Norton.

Barrett, M., Harris, M. \& Chasin, J. (I 99I). Early lexical development and maternal speech: A comparison of children's initial and subsequent uses of words. Fournal of Child Language I8( I), 2 I-40.

Barry, C., Morrison, C. M. \& Ellis, A. W. (I 997). Naming the Snodgrass and Vanderwart Pictures: Effects of age of acquisition, frequency and name agreement. The Quarterly Fournal of Experimental Psychology $\mathbf{5 0 A}(3), 560-85$.

Benedict, H. (I979). Early lexical development: Comprehension and production. Fournal of Child Language 6, I 83-200.

Bird, E. K. R., Gaskell, A., Babineau, M. D. \& Macdonald, S. (2000). Novel word acquisition in children with Down syndrome: Does modality make a difference? Yournal of Communication Disorders 33(3), 24I-66.

Bonvillian, J. D., Orlansky, M. D. \& Folven, R. J. (I990). Early sign language acquisition: Implications for theories of language acquisition. In C. J. Erting (ed.), From gesture to language in hearing and deaf children, 219-32. New York: Springer-Verlag.

Brent, M. R. \& Siskind, J. M. (200I). The role of exposure to isolated words in early vocabulary development. Cognition 81, 33-44.

Brown, G. \& Harris, T. (1978). Social origins of depression. London: Tavistock.

Butterworth, G. (2003). Pointing is the royal road to language for babies. In S. Kita (ed.), Pointing: Where language, culture, and cognition meet, 9-33. Mahwah, $\mathrm{NJ}$ : Erlbaum.

Carey, S. \& Bartlett, E. (I978). Acquiring a single new word. Papers and Reports in Child Language Development I5, I 7-29.

Childers, J. B. \& Tomasello, M. (2003). Children extend both words and non-verbal actions to novel exemplars. Developmental Science 6(2), i 85-90.

Della Corte, M., Benedict, H. \& Klein, D. (1983). The relationship of pragmatic dimensions of mothers' speech to the referential-expressive distinction. Fournal of Child Language ro, $35-43$.

Dijkstra, K., Kaschak, M. P. \& Zwaan, R. A. (2007). Body posture faciltates retrieval of autobiographical memories. Cognition Io2, I 39-49.

D’Odorico, L., Carubbi, S., Salerni, N. \& Calvo, V. (200I). Vocabulary development in Italian children: A longitudinal evaluation of quantitative and qualitative aspects. Fournal of Child Language 28, 35 I-72.

Fenson, L., Dale, P. S., Reznick, J. S., Bates, E., Thal, D. J. \& Pethick, S. J. (I994). Variability in early communicative development. Monographs for the Society for Research in Child Development 59 (Serial No. 242).

Fenson, L., Marchman, V. A., Thal, D. J., Dale, P. S., Reznick, J. S. \& Bates, E. (2007). MacArthur-Bates Communicative Development Inventories: User's guide and technical manual, 2nd edn. Baltimore: Paul H. Brookes.

Furrow, D., Nelson, K. \& Benedict, H. (1979). Mothers' speech to children and syntactic development: Some simple relationships. Fournal of Child Language 6, 423-42.

Goodman, J. C., Dale, P. S. \& Li, P. (2008). Does frequency count? Parental input and the acquisition of vocabulary. Fournal of Child Language 35, 5 I 5-3 I. 
Goodwyn, S. W. \& Acredolo, L. P. (1993). Symbolic gesture versus word-is there a modality advantage for onset of symbol use. Child Development 64(3), 688-70 I.

Goodwyn, S. W. \& Acredolo, L. P. (1998). Encouraging symbolic gestures: A new perspective on the relationship between gesture and speech. In J. Iverson \& S. GoldinMeadow (eds), The nature and function of gesture in children's communication, 6I-73. San Francisco: Jossey-Bass.

Goodwyn, S. W., Acredolo, L. P. \& Brown, C. A. (2000). Impact of symbolic gesturing on early language development. Fournal of Nonverbal Behavior 24(2), 81-103.

Hampson, J. \& Nelson, K. (I 993). The relation of maternal language to variation in rate and style of language-acquisition. Fournal of Child Language 20(2), 3 $13-42$.

Hoff, E. \& Naigles, L. (2002). How children use input to acquire a lexicon. Child Development 73(2), 418-33.

Hoff-Ginsberg, E. (1994). Influences of mother and child on maternal talkativeness. Discourse Processes 18 , I05-I 7 .

Huttenlocher, J., Haight, W., Bryk, A., Seltzer, M. \& Lyons, T. (I991). Early vocabulary growth: Relation to language input and gender. Developmental Psychology 27(2), 236-48.

Iverson, J. M., Capirci, O. \& Caselli, M. C. (1994). From communication to language in two modalities. Cognitive Development 9, 23-43.

Iverson, J. M., Capirci, O., Longobardi, E. \& Caselli, M. C. (I999). Gesturing in mother-child interactions. Cognitive Development $\mathbf{1 4}(\mathrm{I}), 57-75$.

MacWhinney, B. (2000). The CHILDES project: Tools for analyzing talk, 3 rd edn. Mahwah, NJ : Erlbaum.

McNeill, D. (I998). Speech and gesture integration. In J. Iverson \& S. Goldin-Meadow (eds), The nature and functions of gesture in children's communication, I I-29. San Francisco: Jossey-Bass.

Morrison, C. M., Chappell, T. D. \& Ellis, A. W. (I997). Age of acquisition norms for a large set of object names and their relation to adult estimates and other variables. The Quarterly Fournal of Experimental Psychology 50A(3), 528-59.

Namy, L. L., Acredolo, L. \& Goodwyn, S. (2000). Verbal labels and gestural routines in parental communication with young children. Fournal of Nonverbal Behavior 24(2), 63-79.

Nelson, K. (1973). Structure and strategy in learning to talk. Monographs of the Society for Research in Child Development 38( I49).

O’Neill, M., Bard, K. A., Linnell, M. \& Fluck, M. (2005). Maternal gesture with 20-month-old infants in two contexts. Developmental Science 8(4), 352-59.

Rescorla, L. \& Fechnay, T. (I 996). Mother-child synchrony and communicative reciprocity in late-talking toddlers. Fournal of Speech and Hearing Research 39(I), 200-208.

Reznick, J. S. \& Goldfield, B. A. (I994). Diary vs. representative checklist assessment of productive vocabulary. Fournal of Child Language 2I(2), 465-72.

Rosenthal-Robbins, P. (2003). Caregivers' contingent comments to 9-month-old infants: Relationships with later language. Applied Psycholinguistics 24, 22 I-34.

Rowe, M. \& Goldin-Meadow, S. (2009). Differences in early gesture explain SES disparities in child vocabulary size at school entry. Science 323, $95 \mathrm{I}-53$.

Schwartz, R. G. \& Terrell, B. Y. (1983). The role of input frequency in lexical acquisition. Fournal of Child Language 10, 57-64.

Shatz, M. (1982). On mechanisms of language acquisition: Can features of the communicative environment account for development? In E. G. Wanner (ed.), Language acquisition: The state of the art, I02-127. New York: Cambridge University Press.

Tamis-LeMonda, C. S., Bornstein, M. H. \& Baumwell, L. (200I). Maternal responsiveness and children's achievement of language milestones. Child Development 72, 747-67.

Tan, S. H. \& Schafer, G. (2005). Toddlers' novel word learning: Effects of phonological representation, vocabulary size, and parents' ostensive behaviour. First Language 25(2), I $3 \mathrm{I}-55$.

Zammit, M. \& Schafer, G. (in preparation). 'Gesturese': Direct comparison of child- and adult-directed gesture in a variety of contexts. Unpublished manuscript. 